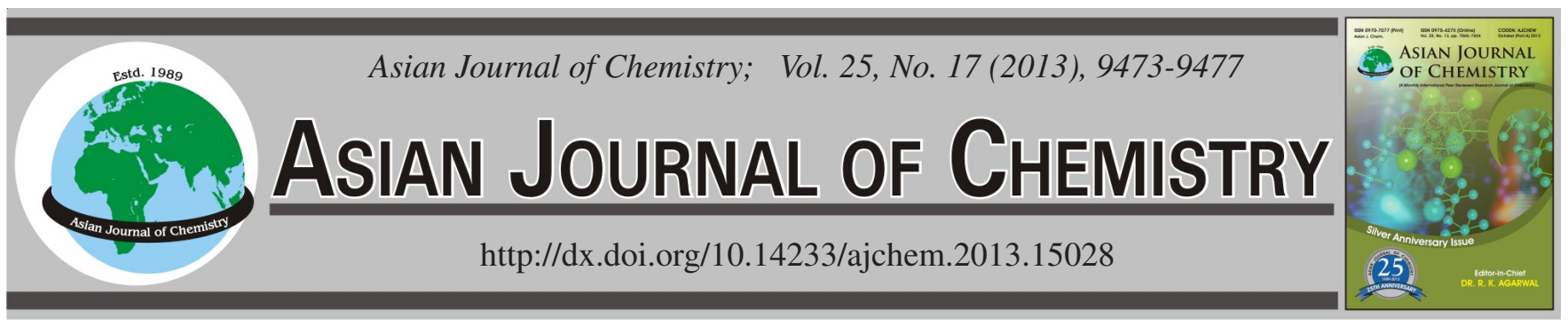

\title{
Enhanced Activity of Hydrochlorination of Acetylene Using Melamine-Modified Activated Carbon Supported Gold Catalyst
}

\author{
Bin Dai ${ }^{*}$, Ning MA, HaiYang Zhang and Xugen WANG
}

School of Chemistry and Chemical Engineering, Shihezi University/Key Laboratory for Green Processing of Chemical Engineering of Xinjiang Bingtuan, Shihezi 832003, Xinjiang Province, P.R. China

*Corresponding author: Tel: +86993 2057277; E-mail: db_tea@shzu.cn; maningttgx@163.com

(Received: 26 December 2012;

Accepted: 1 October 2013)

AJC-14208

\begin{abstract}
A series of modified activated carbon (MAC) was prepared by impregnating with a aqueous solution of melamine and heating under $\mathrm{N}_{2}$ flow at different temperatures. The surface structure of the prepared MAC was characterized by BET, elemental analysis, SEM, FT-IR and XPS. The results of the single carrier activity test showed that MAC exhibited higher activity than activated carbon. Characterization results indicated that the enhanced carrier performance of MAC could be attributed to the presence of nitrogen-containing groups. Subsequently, the supported gold catalysts Au/activated carbon and Au/MAC-0.8-650 were prepared by impregnating with a $\mathrm{H}\left[\mathrm{AuCl}_{4}\right] \cdot 4 \mathrm{H}_{2} \mathrm{O}$ solution which was dissolved in aqua regia. Under the reaction conditions of feed volume ratio $\mathrm{V}(\mathrm{HCl}) / \mathrm{V}\left(\mathrm{C}_{2} \mathrm{H}_{2}\right)=1.15$, temperature 180 ${ }^{\circ} \mathrm{C}, \mathrm{C}_{2} \mathrm{H}_{2}$ hourly space velocity (GHSV) $360 \mathrm{~h}^{-1}$ and gold loading of $0.2 \mathrm{wt} \%$, the acetylene conversion and vinyl chloride monomer selectivity of Au/MAC-0.8-650 were 95 and $>99.91 \%$.
\end{abstract}

Key Words: Modified activated carbon, Melamine, Gold catalyst, Acetylene hydrochlorination.

\section{INTRODUCTION}

The hydrochlorination of acetylene is the main industrial process for producing vinyl chloride monomers (VCMs). Earlier industrial production used mercuric chloride catalysts to promote the reaction of hydrogen chloride and acetylene. However, these catalysts can be short-lived and can lead to severe environmental pollution problems because of their higher toxicity and instability, with the loss of mercuric chloride being the primary catalyst deactivation mechanism ${ }^{1,2}$. Therefore, the development of new low and/or non-mercuric catalysts for the hydrochlorination of acetylene is necessary. Many studies on non-mercuric catalytic systems focused on precious metal salts ${ }^{2-7}$, such as $\mathrm{Au}, \mathrm{Pt}, \mathrm{Rh}, \mathrm{Pd}$, etc. Hutchings et al. ${ }^{4-7}$ found that supported gold catalysts exhibit high activity and stability. Thus, they are often used to promote the reaction of hydrochlorination of acetylene.

Recently, carbon surface modification has drawn considerable attention because of its capability to improve catalyst performance. Activated carbons (ACs) are widely used in catalysis and adsorption because of their chemical stability, well-developed porous structure, large surface area and various surface functional groups ${ }^{8-23}$. It is a clear fact that the activated carbons surface can display acidic, basic and neutral characteristics depending on surface modification and the presence of surface functional groups. In addition, further modification of activated carbons can endow the carbon materials with additional physicochemical functions that can improve their performance in practical applications. Przepiórski ${ }^{13}$ found that activated carbons with nitrogen-containing species have higher adsorption capacities for phenol. Bandosz et al. ${ }^{21}$ reported that the unique feature of materials modified with melamine is their highly efficient adsorption for $\mathrm{H}_{2} \mathrm{~S}$ removal. Zhao et al. ${ }^{23}$ reported that nitrogen-containing carbon materials show excellent performance in gas storages and adsorption for transition metal ions such as $\mathrm{Fe}(\mathrm{III}), \mathrm{Au}(\mathrm{III})$ and $\mathrm{Cr}(\mathrm{VI})$.

In a previous work, we prepared a family of supported low and/or non-mercuric catalysts using various metals and various supports. Zhang et al. ${ }^{2}$ prepared $\mathrm{Au}$ and $\mathrm{Au}$-based bimetallic catalysts. Catalysts with an Au loading of $1 \mathrm{wt} \%$ exhibited satisfactory performance in hydrochlorination of acetylene with $98 \%$ acetylene conversion and $99.8 \%$ selectivity. This study was successful because of the development of a low-cost conversion of $\mathrm{C}_{2} \mathrm{H}_{2}$ with high selectivity and activity. The present study focuses on determining a method that can be used to decrease Au content. Previous studies revealed that increasing the nitrogen content in carbon enhances the activity of a catalyst. Hence, this study hypothesizes that Au catalysts supported on activated carbon modified by nitrogencontaining species reduce $\mathrm{Au}$ content. 
Currently, catalyst for the precious metal salts supported on activated carbons has been intensively investigated, but relatively less work was reported related to modified carbons. In the present study, commercial coconut shell activated carbon was modified using melamine aqueous solution with different impregnation mass ratios ranging from 0.1-1.2 and different calcination temperatures ranging from $550-850^{\circ} \mathrm{C}$. Modified activated carbon (MAC) was used as a support for $\mathrm{Au}$ catalysts and the activities of the catalysts for hydrochlorination of acetylene were measured in a fixed bed microreactor.

\section{EXPERIMENTAL}

Preparation of modified activated carbon: Prior to use, activated carbon was washed with boiled deionized water and then oven-dried at $110{ }^{\circ} \mathrm{C}$ for $24 \mathrm{~h}$. Surface modification of the activated carbon was performed using an incipient wetness impregnation technique with distilled water as a solvent. After the activated carbon was added to a prepared melamine aqueous solution, the mixture was stirred for $24 \mathrm{~h}$ at $85^{\circ} \mathrm{C}$ and then dried for $24 \mathrm{~h}$ at $110^{\circ} \mathrm{C}$. Calcination was performed in a tubular furnace at different temperatures and a heating rate of $5{ }^{\circ} \mathrm{C}$ $\min ^{-1}$ for $0.5 \mathrm{~h}$ under $\mathrm{N}_{2}$ flow to obtain MAC-x-y, where $\mathrm{x}$ represents the impregnation mass ratio (melamine/activated carbon) and y represents the calcination temperature.

Preparation of catalyst: The supported (carbon-supported and MAC-supported) Au catalyst (1 wt \% Au/C) was prepared using an incipient wetness impregnation technique with aqua regia as a solvent. This method is currently the most effective for catalyst preparation ${ }^{2-7}$. A similar preparation method was used to prepare another Au catalyst. A solution of prepared $\mathrm{H}\left[\mathrm{AuCl}_{4}\right] \cdot 4 \mathrm{H}_{2} \mathrm{O}$ in aqua regia was added dropwise to activated carbon and MAC-0.8-650 under stirring, dipped for $10 \mathrm{~h}$ at $80^{\circ} \mathrm{C}$, evaporated in a steam bath and then dried in an oven at $140{ }^{\circ} \mathrm{C}$ for $18 \mathrm{~h}$. The Au catalysts $(0.2 \mathrm{wt} \% \mathrm{Au})$ were denoted as Au/activated carbon and Au/MAC-0.8-650.

Activity measurement procedure: The activity test for the hydrochlorination reaction of acetylene was performed in a stainless steel-fixed bed microreactor with an internal diameter of $10 \mathrm{~mm}$. The pipeline was purged with nitrogen before the reaction to remove water, air and residual gas in the entire system. $\mathrm{C}_{2} \mathrm{H}_{2}\left(11.8 \mathrm{~mL} \mathrm{~min}^{-1}\right)$ and $\mathrm{HCl}\left(11.1 \mathrm{~mL} \mathrm{~min}^{-1}\right)$ were fed through the filter to remove water and impurities using calibrated mass flow controllers in a heated reactor containing $2 \mathrm{~mL}$ of catalyst, giving a $\mathrm{C}_{2} \mathrm{H}_{2}$ hourly space velocity (GHSV) of $360 \mathrm{~h}^{-1}$. The temperature of the reactor was regulated using a CKW-1100 temperature controller purchased from Chaoyang Automation Instrument Factory (Beijing, China). The pressure of the reactants $\mathrm{HCl}$ and $\mathrm{C}_{2} \mathrm{H}_{2}$ ranged from 1.1 bar to 1.2 bar. This range was selected for safety reasons and to test the catalyst under mild conditions. The exit gas mixture was passed through a gas absorption bottle containing $\mathrm{NaOH}$ solution and was analyzed using a Shimadzu GC-2014C chromatograph.

Detection method: The specific surface area and pore size distribution of the samples were analyzed using an ASAP 2020C surface area and porosity analyzer (Micromeritics Instrument Corporation, USA) that uses a nitrogen adsorptiondesorption method. The samples were initially outgassed at approximately $100{ }^{\circ} \mathrm{C}$ for $6 \mathrm{~h}$ and then analyzed with liquid nitrogen adsorption at approximately $77 \mathrm{~K}$. The elemental content of the carbon samples was determined using an element analyzer (VARIO ELIII, Germany). The surface morphology of the samples was examined by scanning electron microscopy (SEM; JSM-6490LV, Electronic Company, Japan) at accelerating voltage of $10 \mathrm{kV}$. For fourier transform infrared spectroscopy (FTIR; Nicolet AVATAR 360), the MAC samples were pressed into a pellet mixed with finely divided $\mathrm{KBr}$ at a ratio of 1:100 and then scanned from $4000-400 \mathrm{~cm}^{-1}$ at a resolution of $4 \mathrm{~cm}^{-1}$. $\mathrm{X}$-Ray photoelectron spectroscopic (XPS) measurements were obtained using an Axis Ultra (Kratos Analytical Ltd., UK).

\section{RESULTS AND DISCUSSION}

Effect of Au catalysts on different carriers: In the same condition, we studied the performance of the Au catalysts supported on three different carriers. They are a new coconut shell activated carbon (AC), pitch-based spherical activated carbon $^{2}$ (SAC), self-regulating mesoporous carbon (OMC). The results are shown in Table-1. The catalysts' activity followed the order: $\mathrm{Au} / \mathrm{SAC}>\mathrm{Au} / \mathrm{AC}>\mathrm{Au} / \mathrm{OMC}$. The catalysts' activity of $\mathrm{Au} / \mathrm{SAC}$ is the best, but we chose a low-cost coconut shell activated carbon as carrier in the next experiment.

TABLE-1

CATALYTIC PERFORMANCE OF GOLD CATALYSTS ON DIFFERENT CARRIERS $\left(\mathrm{C}_{2} \mathrm{H}_{2}(\mathrm{GHSV}): 360 \mathrm{~h}^{-1} ; \mathrm{T}: 423 \mathrm{~K} ; \mathrm{t}=10 \mathrm{~h}\right)$

$\begin{array}{cccc}\text { Catalyst } & \mathrm{XC}_{2} \mathrm{H}_{2}(\%) & \mathrm{SC}_{2} \mathrm{H}_{2}(\%) & \text { References } \\ \mathrm{Au} / \mathrm{AC} & 96.65 & 99.98 & \text { This work } \\ \mathrm{Au} / \mathrm{SAC} & 99.90 & 99.97 & 2 \\ \mathrm{Au} / \mathrm{OMC} & 70.36 & 99.89 & \text { This work }\end{array}$

Carrier activity: The activity test conditions of the single carrier were as follows: 1.15 feed volume ratio $\mathrm{V}(\mathrm{HCl}) / \mathrm{V}$ $\left(\mathrm{C}_{2} \mathrm{H}_{2}\right), 150{ }^{\circ} \mathrm{C}$ temperature and $30 \mathrm{~h}^{-1} \mathrm{GHSV}\left(\mathrm{C}_{2} \mathrm{H}_{2}\right)$.

The results of the activity tests on the fresh and melaminetreated activated carbons are shown in Fig. 1. The calcination temperature proved to be quite important in carrier activity. Compared with the untreated activated carbon, each MAC demonstrated enhanced activity of acetylene hydrochlorination to VCM. The enhancement in $\mathrm{C}_{2} \mathrm{H}_{2}$ conversion depended on the presence of nitrogen-containing groups. The introduction of nitrogen into MAC by melamine impregnation and heating treatment improved the performance of these carbons. However, high temperatures could aggravate the decomposition of melamine. Hence, the activities were in the following sequence: activated carbon $<$ MAC-0.5-550 < MAC-0.5-850 < MAC0.5-750 < MAC-0.5-650. This temperature was selected based on the assumption that melamine decomposition occurs at 345 $360{ }^{\circ} \mathrm{C}$, the relatively low calcination temperature of $650{ }^{\circ} \mathrm{C}$ was likely not sufficient for the complete decomposition of nitrogen-containing species in the presence of activated carbon. The single carrier activity provided the best fit for the MAC calcined at $650^{\circ} \mathrm{C}$.

As shown in Fig. 2, the addition of nitrogen species to activated carbon caused the carrier to have a higher conversion of $\mathrm{C}_{2} \mathrm{H}_{2}$ than activated carbon. This finding suggests that the carrier activity and lifetime for hydrochlorination of acetylene could still be increased. Moreover, the activity increased with 


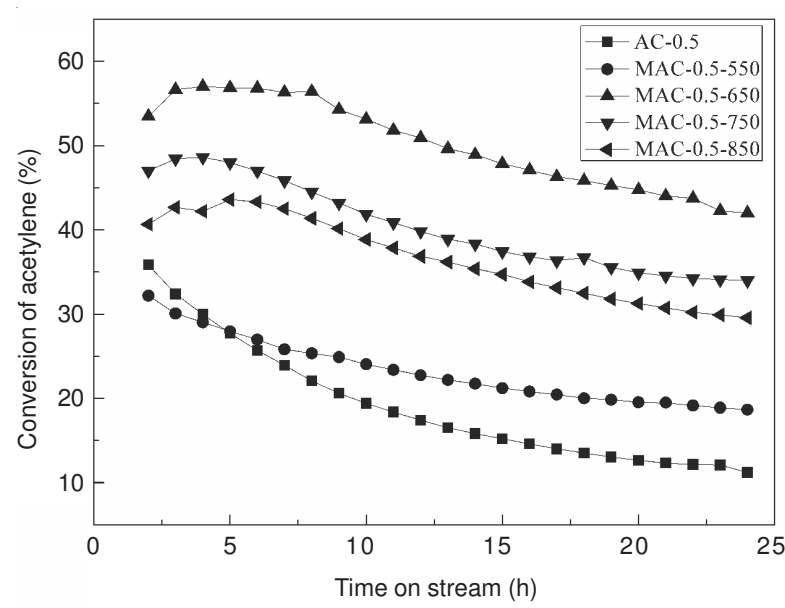

Fig. 1. Acetylene conversion by MAC with different calcination temperature. Reaction conditions: temperature $(\mathrm{T})=150{ }^{\circ} \mathrm{C} ; \mathrm{C}_{2} \mathrm{H}_{2}$ hourly space velocity $(\mathrm{GHSV})=30 \mathrm{~h}^{-1}$; feed volume ratio $\mathrm{V}(\mathrm{HCl}) /$ $\mathrm{V}\left(\mathrm{C}_{2} \mathrm{H}_{2}\right)=1.15$

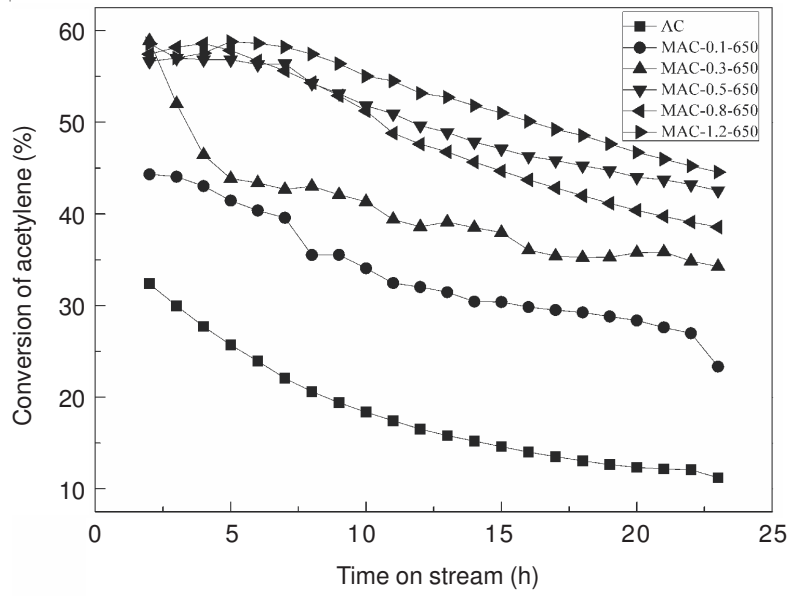

Fig. 2. Acetylene conversion by MAC with different impregnation mass ratio. Reaction conditions: temperature $(\mathrm{T})=150{ }^{\circ} \mathrm{C} ; \mathrm{C}_{2} \mathrm{H}_{2}$ hourly space velocity $(\mathrm{GHSV})=30 \mathrm{~h}^{-1}$; feed volume ratio $\mathrm{V}(\mathrm{HCl}) / \mathrm{V}\left(\mathrm{C}_{2} \mathrm{H}_{2}\right)$ $=1.15$

increasing melamine content. MAC-0.8-650 exhibited a satisfactory performance, with an almost $30 \%$ higher $\mathrm{C}_{2} \mathrm{H}_{2}$ conversion than activated carbon within $24 \mathrm{~h}$. Further increasing the melamine content did not improve the activity. These results indicate that the optimal impregnation mass ratio of $\mathrm{MAC}$ is 0.8 .

Characterization of carrier: Surface modification using nitrogen-containing species may result in changes in the pore structure. The pore structure parameters of the activated carbon and MAC are shown in Table-2. As expected, the BrunauerEmmett-Teller surface area of MAC significantly reduced from 1219 to $833 \mathrm{~m}^{2} \mathrm{~g}^{-1}$ after modification and decreased gradually as the nitrogen species increased. These findings indicate that the pores were blocked by the nitrogen products of melamine partial decomposition.

Table-3 presents the elemental analysis of the samples. The samples with a fixed amount of melamine but with different calcination temperatures show that MAC-0.5-650 has a relatively high nitrogen content (5.28\%), which is in accordance with the activity test results. The elemental analysis (Table-3) also shows that the nitrogen content of MAC with various impregnation mass ratios but with a constant calcination tempe-
TABLE-2

PORE STRUCTURE PARAMETERS OF ACTIVATED CARBON AND MODIFIED ACTIVATED CARBON

\begin{tabular}{cccc}
\hline Sample & $\begin{array}{c}\mathrm{S}_{\mathrm{BET}} \\
\left(\mathrm{m}^{2} / \mathrm{g}\right)\end{array}$ & $\begin{array}{c}\text { Total pore volume } \\
\left(\mathrm{cm}^{3} / \mathrm{g}\right)\end{array}$ & $\begin{array}{c}\text { Average pore } \\
\text { diameter }(\mathrm{nm})\end{array}$ \\
\hline Activated carbon & 1219 & 0.9751 & 2.33 \\
MAC-0.1-650 & 1103 & 0.9750 & 2.35 \\
MAC-0.3-650 & 936 & 0.9750 & 2.34 \\
MAC-0.5-650 & 988 & 0.9750 & 2.37 \\
MAC-0.8-650 & 906 & 0.9749 & 2.34 \\
MAC-1.2-650 & 833 & 0.9748 & 2.37 \\
\hline
\end{tabular}

TABLE-3

ELEMENTAL ANALYSIS OF ACTIVATED CARBON AND MODIFIED ACTIVATED CARBON

\begin{tabular}{ccccc}
\hline Sample & $\mathrm{N}(\%)$ & $\mathrm{C}(\%)$ & $\mathrm{S}(\%)$ & $\mathrm{H}(\%)$ \\
\hline Activated carbon & 0.37 & 82.98 & 0.26 & 0.58 \\
MAC-0.5-550 & 1.26 & 87.16 & 0.21 & 0.94 \\
MAC-0.5-650 & 5.29 & 80.68 & 0.15 & 0.91 \\
MAC-0.5-750 & 3.93 & 83.30 & 0.14 & 0.63 \\
MAC-0.5-850 & 3.24 & 82.04 & 0.12 & 0.75 \\
MAC-0.1-650 & 2.12 & 82.14 & 0.09 & 0.59 \\
MAC-0.3-650 & 3.21 & 78.37 & 0.06 & 0.50 \\
MAC-0.8-650 & 6.65 & 78.44 & 0.11 & 0.89 \\
MAC-1.2-650 & 8.48 & 79.65 & 0.10 & 0.81 \\
\hline
\end{tabular}

rature increased significantly because of the presence of melamine decomposition nitrogen-containing products. The nitrogen content of MAC-1.2-650 reached up to $8.48 \%$.

SEM images of the samples (Fig. 3) show that no significant differences exist in the surface morphology of activated carbon (Fig. 3a) and MAC-0.1-650 (Fig. 3b), except for some apparent pore narrowing in MAC. This result suggests that they have similar surface structures. MAC-0.8-650 (Fig. 3d) compared with MAC-0.1-650 had a visual impact in terms of surface morphology. This finding may be attributed to the pore blockage in the micropores caused by the formation of melamine decomposition products during calcination. However, MAC-0.8-650 had wider pores than MAC-0.8 (Fig. 3c), implying that the heat treatment partly removed some of the melamine decomposition products lodged in the micropores.
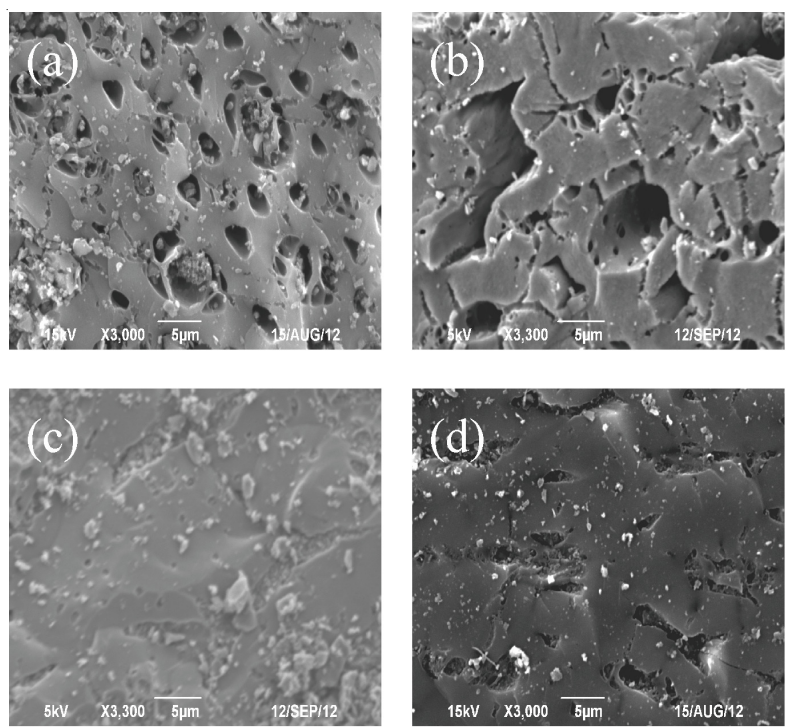

Fig. 3. SEM images of samples. (a) activated carbon, (b) MAC-0.1-650, (c) MAC-0.8 and (d) MAC-0.8-650 
Fig. 4 shows the FTIR spectra of untreated actived carbon and modified samples (AC, AC-0.1-650, AC-0.3-650, AC-0.5650, AC-0.8-650and AC-1.2-650). The spectra of the two samples showed some marked similarities. A strong absorption at 3850-3300 $\mathrm{cm}^{-1}$ was detected on the spectra of both samples, which could be assigned to $\mathrm{O}-\mathrm{H}$ stretching vibration ${ }^{9-11}$. The band at $c a .2900 \mathrm{~cm}^{-1}$ probably corresponded to C-H stretching vibration $^{12}$. The bands at $1750-1630$ and $1600-1450 \mathrm{~cm}^{-1}$ could be assigned to $\mathrm{C}=\mathrm{O}$ and $\mathrm{C}=\mathrm{C}$ groups ${ }^{12}$. However, differences in the spectra of the two samples can also be observed. Peaks related to nitrogen-containing groups were observed in the modified samples. Melamine treatment caused some changes in the spectra of modified samples. A sharp bands at $3742 \mathrm{~cm}^{-1}$ related to $\mathrm{N}-\mathrm{H}$ stretching vibrations was observed for all modified samples. The spectra of MAC-0.8-650 showed a band at $1540 \mathrm{~cm}^{-1}$, which may be related to $\mathrm{C}=\mathrm{N}$ groups. In addition, bands at 1158 and $1465 \mathrm{~cm}^{-1}$ may be associated with $\mathrm{C}-\mathrm{N}$ (amide) and $\mathrm{N}-\mathrm{H}$ groups, respectively ${ }^{10-13}$. These results indicate that melamine modification can produce new nitrogen surface complexes and some basic groups.

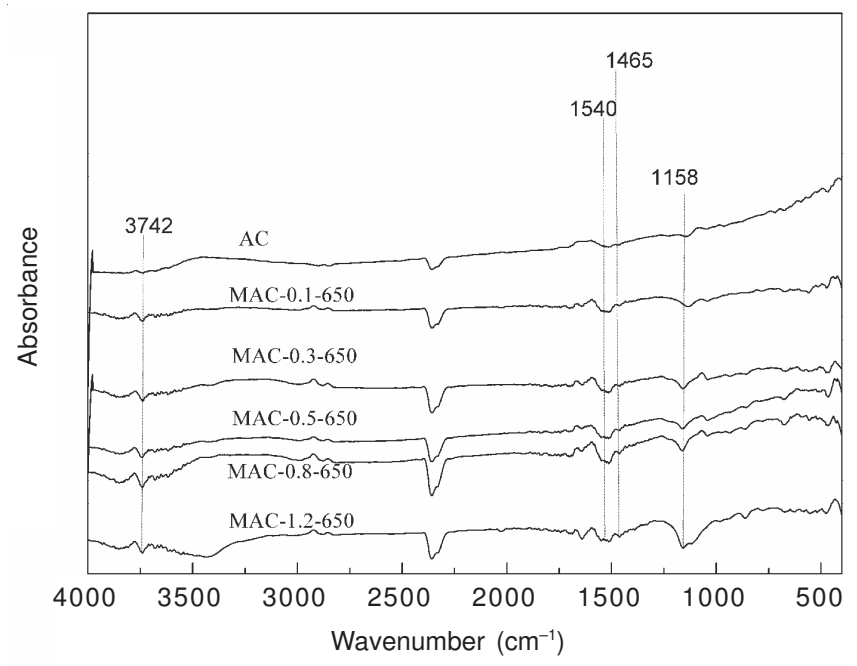

Fig. 4. FTIR spectra for activated carbon and MAC sample

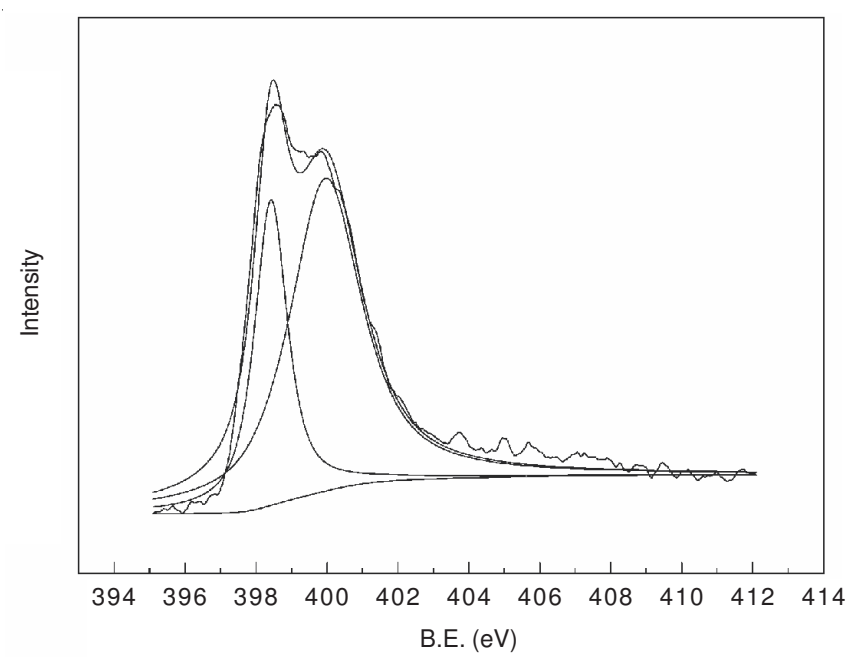

Fig. 5. XPS spectra for MAC-0.8-650 sample

Fig. 5 shows the XPS N(1s) measurements for MAC-0.8650 . The peak at $398.5 \mathrm{eV}$ can be assigned to pyridine nitrogen species and the band at $400.5 \mathrm{eV}$ corresponds to pyrrole $\mathrm{N}^{22}$. The presence of nitrogen-containing groups in MAC could increase basicity, thus improving catalytic performance.

Catalytic activity and selectivity: Fig. 6 shows that the $\mathrm{Au} /$ activated carbon $(0.2 \mathrm{wt} \% \mathrm{Au})$ catalyst exhibited satisfactory performance, with almost $88 \% \mathrm{C}_{2} \mathrm{H}_{2}$ conversion and $>99.98 \%$ VCM selectivity within $24 \mathrm{~h}$. In comparison with the results of Zhang et al. ${ }^{2}$. We choose a low cost activated carbon than their pitch-based spherical activated carbon also had well $\mathrm{C}_{2} \mathrm{H}_{2}$ conversion with an Au loading form 1.0 to $0.2 \mathrm{wt} \%$. However, the addition of nitrogen-containing species to activated carbon slightly decreased the induction period of hydrochlorination and increased the conversion rate of the catalysts. The $\mathrm{Au} /$ MAC-0.8-650 (0.2 wt \% Au) catalyst exhibited a relatively high activity, with $95 \% \mathrm{C}_{2} \mathrm{H}_{2}$ conversion and $99.91 \% \mathrm{VCM}$ selectivity. Our experiment shows that the $\mathrm{C}_{2} \mathrm{H}_{2}$ conversion of the $\mathrm{Au} / \mathrm{MAC}-0.8-650$ catalyst was higher than that of the untreated $\mathrm{Au} /$ activated carbon catalyst. The results also confirmed our hypothesis by the introduction of nitrogen-containing species on activated carbon to reduce the Au content and then improve the acetylene conversion rate is feasible.
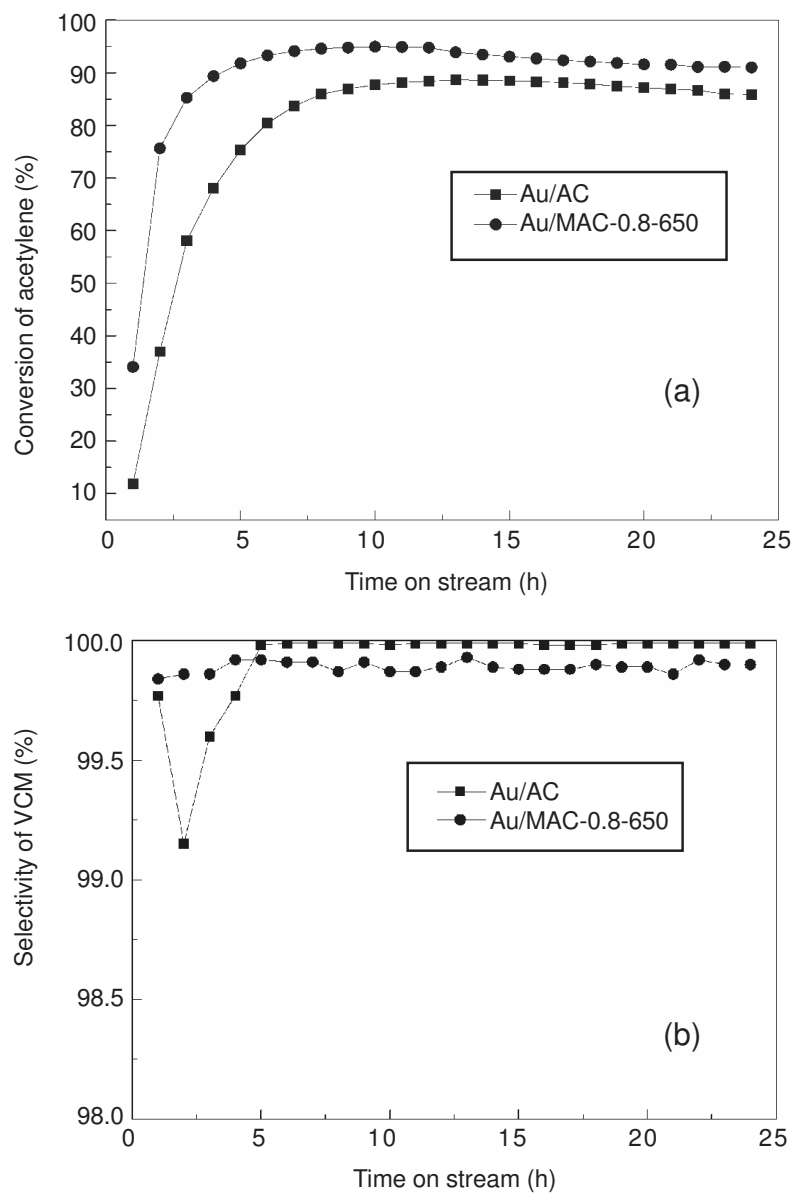

Fig. 6. Catalytic performance of Au/activated carbon and Au/MAC catalysts. Reaction conditions: temperature $(\mathrm{T})=180{ }^{\circ} \mathrm{C} ; \mathrm{C}_{2} \mathrm{H}_{2}$ hourly space velocity $(\mathrm{GHSV})=360 \mathrm{~h}^{-1} ;$ Feed volume ratio $\mathrm{V}(\mathrm{HCl}) /$ $\mathrm{V}\left(\mathrm{C}_{2} \mathrm{H}_{2}\right)=1.15$

The deactivation mechanism of $\mathrm{AuCl}_{3}$ catalysts for hydrochlorination of acetylene was studied by Zhang et al. ${ }^{3}$. $\mathrm{HCl}$ and the $\mathrm{AuCl}_{3}$ dimer co-catalyze $\mathrm{C}_{2} \mathrm{H}_{2}$ and produce the 
intermediate vinyl chloride. If $\mathrm{HCl}$ could not be adsorbed on the Au site, the intermediate chlorovinyl will be difficult to desorb from the Au catalyst. The catalytic activity of the $\mathrm{AuCl}_{3}$ catalyst would be reduced because the active $\mathrm{Au}$ sites are occupied. Thus, the efficient adsorption of $\mathrm{HCl}$ on the $\mathrm{Au}$ site is necessary to retain the activity of the $\mathrm{AuCl}_{3}$ catalyst for hydrochlorination of acetylene. Furthermore, the current experiment shows that the presence of nitrogen-containing groups in melamine-modified activated carbon increases the basicity of MAC, thereby improving $\mathrm{HCl}$ adsorption. The modified $\mathrm{Au}$ catalyst can efficiently adsorb $\mathrm{HCl}$ molecules rather than $\mathrm{C}_{2} \mathrm{H}_{2}$, thus exhibiting satisfactory catalytic performance of hydrochlorination of acetylene.

\section{Conclusion}

Activated carbon was modified by aqueous solution of melamine at various calcination temperatures and with different impregnation mass ratios. Characterization results from the elemental analysis, FTIR and XPS suggested that nitrogencontaining groups were formed and incorporated into the surface of activated carbon. Carrier activity tests showed that the hydrochlorination of acetylene by activated carbon was significantly improved in the presence of nitrogen species. Moreover, the optimal calcination temperature and impregnation mass ratio of MAC were found to be $650{ }^{\circ} \mathrm{C}$ and 0.8 , respectively. Activated carbon and MAC-0.8-650 were impregnated with $\mathrm{Au}$ and then tested for hydrochlorination of acetylene. The Au/MAC-0.8-650 catalyst exhibited the best performance with $\mathrm{ca} .95 \%$ acetylene conversion and $99.91 \%$ VCM selectivity had the lower Au content. This finding may be attributed to the presence of nitrogen-containing groups in the melaminemodified activated carbon, which increased the basicity of MAC and thus improved its adsorption and catalytic performance.

\section{ACKNOWLEDGEMENTS}

The authors are grateful for their financial support from State Key Development Program for Basic Research of China
(No. 2010CB234605, 2012CB720302) and Program for Changjiang Scholars and Innovative Research Team in University (No. IRT1161).

\section{REFERENCES}

1. Q. Yang, Q. Luo, W.W. Jiang and H. Chen, Sichuan Chem. Ind., 10, 13 (2007).

2. H.Y. Zhang, B. Dai, X.G. Wang, L.L. Xu and M.Y. Zhu J. Ind. Eng. Chem., 18, 49 (2012).

3. J.L. Zhang, Z.H. He, W. Li and Y. Han, RSC Adv., 2, 4814 (2012).

4. G.J. Hutchings, Catal. Today, 72, 1 (2002).

5. M. Conte, A.F. Carley, C. Heirene, D.J. Willock, P. Johnston, A.A. Herzing, C.J. Kiely and G.J. Hutchings, J. Catal., 250, 231 (2007).

6. M. Conte, A.F. Carley, C. Heirene and G.J. Hutchings, J. Catal. Lett., 124, 165 (2008).

7. M. Conte, A.F. Carley, G. Attard, A.A. Herzing, C.J. Kiely and G.J. Hutchings, J. Catal., 257, 190 (2008).

8. C.Y. Hou, L.R. Feng and F.L. Qiu, Chin. Chem. Lett., 20, 865 (2009).

9. S.X. Liu and R. Wang, J. Porous Mater., 18, 99 (2011).

10. F.W. Shaarani and B.H. Hameed, Chem. Eng. J., 169, 180 (2011).

11. A. Ramadevi and K. Srinivasan, Asian J. Chem., 17, 2621 (2005).

12. Z.J. Zhang, M.Y. Xu, H.H. Wang and Z. Li, Chem. Eng. J., 160, 571 (2010).

13. J. Przepiórski, J. Hazard Mater. B, 135, 453 (2006).

14. X.Y. Li, D. Ma and X.H. Bao, Chin. J. Catal., 29, 259 (2008).

15. J. Przepio'rski, W. Skrodzewicz and A.W. Morawski, Appl. Surf. Sci., 225, 235 (2004).

16. Y.H. Zhou, X.Y. Li, X.L. Pan and X.H. Bao, J. Mater. Chem., 22, 14155 (2012).

17. M. Anbia and V. Hoseini, J. Nat. Gas Chem., 21, 339 (2012).

18. F.R. Li, H.H. Yi, X.L. Tang, P. Ning, Q.F. Yu and D.J. Kang, J. Rare Earth, 28, 334 (2010).

19. J. De Celis, N.E. Amadeo and A.L. Cukierman, J. Hazard Mater, 161, 217 (2009).

20. Y.Q. Cong and Z.C. Wu, Chin. Chem. Lett., 18, 1013 (2007).

21. A. Bagreev, J.A. Menendez, I. Dukhno, Y. Tarasenko and T.J. Bandosza, Carbon, 42, 469 (2004).

22. E. Raymundo-Pinero, D. Cazorla-Amoros, A. Linares-Solano, J. Find, U. Wild and R. Schlogl, Carbon, 40, 597 (2002).

23. J.P. Yang, Y.P. Zhai, Y.H. Deng, D. Gu, Q. Li, Q.L. Wu, Y. Huang, B. Tu and D.Y. Zhao, J. Colloid Interf. Sci., 342, 579 (2010). 